\title{
The Evaluation of Anosognosia in Stroke Patients
}

\author{
M.D. Orfei ${ }^{a} \quad$ C. Caltagirone ${ }^{a, b} \quad$ G. Spalletta ${ }^{a, b}$
}

a RCCS Santa Lucia Foundation and b ${ }^{b}$ Department of Neuroscience, University of Rome Tor Vergata, Rome, Italy

\section{Key Words}

Anosognosia, assessment $\cdot$ Stroke rehabilitation

\begin{abstract}
Background: Anosognosia in stroke patients showed a relevant detrimental effect on the rehabilitation course and patients' quality of life, especially in those with brain injury. Although a number of reliable scales for the assessment of anosognosia in stroke and traumatic brain injury have been developed, at present no single measure fully explores the multifaceted nature of the phenomenon. Method: A PubMed search with appropriate terms was carried out in order to critically review the issue. Results: The main dimensions to consider in the investigation of anosognosia in brain-injured patients are (a) awareness of deficit and related functional implications, (b) modality specificity, (c) causal attribution, (d) expectations of recovery, (e) implicit knowledge and (f) differential diagnosis with psychological denial. Time elapsed from stroke, aetiology, laterality, aphasia and clinical complications may influence all these characteristics and must be taken into consideration. Finally, an adequate association of the anosognosia evaluation with other neuropsychological and behavioural aspects is relevant for a modern holistic approach to the patient. Conclusions: This review is meant to stimulate the development of a new comprehensive assessment procedure for anosognosia in brain injury and particularly in stroke, in order to catch the multidimensionality of the phenomenon and to shape rehabilitation programmes suitable to the specific clinical features of every single patient.

Copyright $\odot 2009$ S. Karger AG, Basel
\end{abstract}

\section{Introduction}

Anosognosia is a self-awareness disorder which prevents brain-damaged patients from recognizing the presence or appreciate the severity of deficits in sensory, perceptual, motor, behavioural or cognitive functioning, which are evident to clinicians and caregivers $[1,2]$. In particular, anosognosia following stroke [3] has gained importance for its striking phenomenology, its incidence in the stroke population and because it is detrimental to the recovery and rehabilitation course [4-6]. Thus, the assessment of anosognosia is fundamental. In fact, modern conceptualizations of awareness deficits in braindamaged patients highlight the complex and multilevel nature of these clinical phenomena [3]. For instance, the pyramidal model proposed by Crosson et al. [7] hypothesizes 3 possible levels of awareness deficits, with specific clinical and rehabilitative implications for each. In the last 30 years, a number of high-quality measures have been proposed, but most of them focus on specific aspects, leaving other dimensions of anosognosia unexplored. Thus, at present no single scale is able to fully explore all the components of poor awareness of deficit. This is a relevant issue from a clinical perspective, because a lack of exhaustive diagnostic procedures may potentially affect the development of specific and efficient rehabilitation programmes. In addition, heterogeneous selection criteria and assessment modalities contribute to gather highly variable epidemiological data [3] and prevent a deeper knowledge of awareness processes and impairments.

\section{KARGER}

Fax +4161306 1234 E-Mail karger@karger.ch www.karger.com
(C) 2009 S. Karger AG, Basel

1015-9770/09/0273-0280\$26.00/0

Accessible online at:

www.karger.com/ced
Gianfranco Spalletta, MD, $\mathrm{PhD}$

IRCCS Santa Lucia Foundation, Laboratory of Clinical and Behavioural Neurology

Via Ardeatina 306

IT-00179 Rome (Italy)

Tel./Fax +39 065150 1575, E-Mail g.spalletta@hsantalucia.it 
Table 1. Studies on anosognosia in relationship to different aetiopathogeneses

\begin{tabular}{lll}
\hline Stroke & Traumatic brain injury & $\begin{array}{l}\text { Combined aetiologies } \\
\text { (stroke, traumatic brain injury and others) }\end{array}$ \\
\hline Starkstein et al. [8], 1992 & Prigatano and Altman [27], 1990 & Bisiach et al. [43], 1986 \\
Stone et al. [9], 1993 & Sherer et al. [28], 1998 \\
Ramachandran [10], 1995 & Leathem et al. [29], 1998 & Borgaro and Prigatano [45], 2003 \\
Pedersen et al. [6], 1996 & Fleming et al. [30], 1998 & Kortte et al. [46], 2003 \\
Maeshima et al. [11], 1997 & Ranseen et al. [31], 1990 & Fisher et al. [47], 2004 \\
Jehkonen et al. [12], 2000 & Sherer et al. [32], 2003 & Fisher et al. [48], 2004 \\
Hartman-Maeir et al. [13], 2001 & Bogod et al. [33], 2003 & Noé et al. [49], 2005 \\
Appelros et al. [14], 2002 & Hart et al. [34], 2004 & \\
Appelros et al. [15], 2003 & Evans et al. [35], 2005 & \\
Hartman-Maeir et al. [16], 2003 & Murrey et al. [36], 2005 & \\
Farnè et al. [17], 2004 & Sawchyn et al. [37], 2005 & \\
Marcel et al. [18], 2004 & Sherer et al. [38], 2005 & \\
Baier et al. [19], 2005 & Kurtz et al. [39], 2006 & \\
Berti et al. [20], 2005 & Schmitz et al. [40], 2006 & \\
Karnath et al. [21], 2005 & Pagulayan et al. [41], 2007 & \\
Nimmo-Smith et al. [22], 2005 & Dirette and Plaisier [42], 2007 \\
Barskova et al. [23], 2006 & \\
Santos et al. [24], 2006 & \\
Appelros et al. [25], 2007 & \\
Spalletta et al. [26], 2007 & \\
\hline
\end{tabular}

This paper aims to draw attention to a number of issues to be considered in the assessment of anosognosia and to encourage the development of new and more efficient diagnostic procedures able to fit modern knowledge on awareness phenomena. Thus, on the basis of the recent studies in this area, the most remarkable methodological issues and specific clinical factors are listed and debated.

For our purposes, the database was selected using Pubmed Services utilizing the key words 'stroke', 'traumatic brain injury' and 'anosognosia'. The bibliographies of all related articles were searched. All the pertinent literature considered to be of relevant scientific interest by MDO and GS concerning the assessment of diagnosis and severity of anosognosia was selected. We chose a sample of studies, spanning from 1986 to 2007, to examine some salient methodological issues (table 1).

\section{Classical versus More Recent Approach to the Assessment of Anosognosia in Stroke}

The modern concept of anosognosia concerns a multidimensional phenomenon which includes a wider range of related factors. This is quite evident in research on impaired self-awareness in other medical conditions. For instance, causal attribution of the deficit, evaluation of functional implications in activities of daily living, expectations of recovery, changes in various ability domains (sensorimotor, but also cognitive, behavioural and interpersonal) and adherence to the treatment are part and parcel of the definition of poor awareness of illness in traumatic brain injury (TBI), dementia and schizophrenia, and as such they are commonly investigated [50]. In contrast, these dimensions are mostly disregarded in stroke, where the best-known questionnaires for anosognosia in stroke, such as Cutting's questionnaire [51], Bisiach's Scale [43], the Anosognosia Questionnaire [8], the Anosognosia for Hemiplegia Questionnaire [52] and the Structured Awareness Interview [18], are polarized on the awareness of sensorimotor deficit per se, consistently with the original definition of anosognosia [53]. In addition, the complexity of an awareness deficit is supported by neuro-anatomic studies, which suggest that anosognosia is due to the impairment of a wide neural net including a number of cerebral circuits [54-57].

Thus, the development of a wider diagnostic perspective on anosognosia in stroke, consistent with the recent evolution of the concept of anosognosia, is required. To date, the measures for anosognosia in stroke, although quite reliable, are not very diversified, as they are all based on the clinician's judgement, provide very similar items 
and focus on nearly the same few themes. In contrast, in other medical conditions, such as TBI and dementia, more flexible anosognosia trials allow clinicians to monitor the evolution of the phenomenon under a number of aspects and also in daily living after discharge. Of course, given proper operational adjustments, the structure of these measures and the general issues they investigate can provide fruitful suggestions to improve the assessment of anosognosia in stroke.

\section{Specific Methodological Issues}

What to Assess?

In a multifaceted perspective, the main dimensions of anosognosia to investigate are as follows.

Modality Specificity. It refers to the unawareness of specific aspects of the illness but not of others [58]. For instance, the patient can be aware of a cognitive deficit but not of a more evident sensorimotor deficit. This is why, unlike present questionnaires for anosognosia in stroke, we suggest the inclusion of a number of specific items to assess the awareness of various deficits, specifically sensorimotor, cognitive, affective and behavioural deficits.

Causal Attribution. The patient can be aware of the deficit but disregard the real causes, attributing the impairment to other factors (e.g. a flu or laziness) or judging the pathological event as less severe than its real nature.

Awareness of Functional Implications, Expectations of Recovery and Need for Treatment. In fact, the patient can admit verbally to suffer from a deficit but not realize its pragmatic consequences, asserting that he/she is capable of doing everything he/she could do before the injury. Also, anosognosic patients can ask insistently to be discharged because they are sane [59] or can refuse to attend the rehabilitative programmes and clinicians' prescriptions.

Implicit Knowledge. This implies an inconsistency between the patient's verbal answers and behaviours $[4,18]$. A frequent contradiction in anosognosic hemiplegic patients is the verbal assertion that they are able to walk but at the same time refuse to leave the wheelchair. Thus, the inclusion of both verbal and non-verbal items is essential to reveal a possible dissociation between explicit and implicit knowledge $[18,10,60]$. For instance, with regard to motor deficits, the request to perform some actions, such as to lift the paralysed arm/leg and to compare it with the sound one, to choose between unimanual and bimanual/ bipedal tasks, can be very informative. In fact, an anosog- nosic patient is expected to choose a bimanual task, while an underlying implicit knowledge of the deficit would compel him/her to privilege unimanual tasks [10]. Table 2 points out that $70 \%$ of studies on anosognosia in stroke adopted a combined (i.e. verbal and non-verbal) strategy of assessment, although only $29 \%$ of them actually required more articulated motor procedures. In order to let the implicit knowledge emerge, the alternate use of first/third-person questions about the deficit can also be used. In fact, some anosognosic patients tend to answer more correctly when asked to evaluate the deficit as referred to another person than when referred to him/ herself. In the present study, only one study adopting this approach was found [18]. With specific regard to cognitive deficits, the patient's discrepancy between predicted and actual performance in a cognitive task can be very informative, since it does not require any significant intervention of others [61, 62].

Concurrent Awareness Phenomena. These include neglect, confabulations, bodily delusions, misoplegia or anosodiaphoria. Some classical anosognosia scales include items about these issues, but they are generally not sufficiently thorough or discriminating. In particular, the diagnosis of neglect requires attention, given the high co-occurrence with anosognosia and the partial overlap of brain areas involved [20]. Also, it is important to evaluate the various forms of neglect (e.g. visual, tactile, personal, spatial, extinction) [63], in order to clarify whether some of them are related to specific dimensions of anosognosia and to better define the still debated matter of the co-occurrence of these two phenomena.

Differential Diagnosis between Anosognosia and Denial. This issue should not be undervalued, especially in case of a mild to moderate deficit. At first glance, anosognosia and denial produce the same effect, that is the disavowal or the minimization of the deficit, but at a deeper analysis some salient behavioural differences emerge [ 46 , 64].

\section{Who to Assess?}

The present review stresses a fair variability in the characteristics of the populations considered in different studies. This can account for the high variability in findings and makes data hard to compare. In particular, when selecting a sample, the following aspects have to be considered.

Mixed Brain Injury Aetiology. Of the total sample of studies on anosognosia that we considered, $47 \%$ recruited only stroke patients, $37 \%$ only TBI subjects and $16 \%$ combined various medical conditions, such as stroke, TBI or 
Table 2. Characteristics of studies on anosognosia in stroke

\begin{tabular}{|c|c|c|c|c|c|c|}
\hline Authors & Sample & $\begin{array}{l}\text { Time of } \\
\text { assessment }\end{array}$ & $\begin{array}{l}\text { Side of } \\
\text { lesion }\end{array}$ & $\begin{array}{l}\text { Verbal/non-verbal } \\
\text { trials }\end{array}$ & Follow-up & $\begin{array}{l}\text { Language } \\
\text { disorders }\end{array}$ \\
\hline Starkstein et al. [8], 1992 & 80 subjects & mean 6 days & $\mathrm{R}+\mathrm{L}$ & $\mathrm{V}+$ simple NV & no & not included \\
\hline Stone et al. [9], 1993 & 171 subjects & $2-3$ days & $\mathrm{R}+\mathrm{L}$ & u.s. & no & u.s. \\
\hline Ramachandran [10], 1995 & 4 subjects & $<8$ days & $\mathrm{R}$ & $\mathrm{V}+\mathrm{NV}$ & no & u.s. \\
\hline Pedersen et al. [6], 1996 & 566 subjects & 1-7 days & $\mathrm{R}+\mathrm{L}$ & $\mathrm{V}+$ simple NV & no & not included \\
\hline Maeshima et al. [11], 1997 & 50 subjects & $<30$ days & $\mathrm{R}$ & $\mathrm{V}$ & yes & u.s. \\
\hline Jehkonen et al. [12], 2000 & 57 subjects & $<10$ days & $\mathrm{R}$ & $\mathrm{V}+$ simple NV & yes & not included \\
\hline Hartman-Maeir et al. [13], 2001 & 46 subjects & 4-8 weeks & $\mathrm{R}+\mathrm{L}$ & $\mathrm{V}+\mathrm{NV}$ & yes & included \\
\hline Appelros et al. [14], 2002 & 282 subjects & $1-4$ days & $\mathrm{R}+\mathrm{L}$ & $\mathrm{V}+$ simple NV & no & not included \\
\hline Appelros et al. [15], 2003 & 282 subjects & $1-4$ days & $\mathrm{R}+\mathrm{L}$ & $\mathrm{V}+$ simple NV & no & not included \\
\hline Hartman-Maeir et al. [16], 2003 & 60 subjects & 4-8 weeks & $\mathrm{R}+\mathrm{L}$ & $\mathrm{V}$ & yes & not included \\
\hline Farnè et al. [17], 2004 & 33 subjects & $<6$ weeks & $\mathrm{R}$ & $\mathrm{V}$ & yes & u.s. \\
\hline Marcel et al. [18], 2004 & 64 subjects & mean 67 days & $\mathrm{R}+\mathrm{L}$ & $\mathrm{V}+\mathrm{NV}$ & no & not included \\
\hline Baier et al. [19], 2005 & 128 subjects & $<15$ days & $\mathrm{R}+\mathrm{L}$ & $\mathrm{V}+$ simple NV & no & not included \\
\hline Berti et al. [20], 2005 & 30 subjects & $<60$ days & $\mathrm{R}$ & $\mathrm{V}+$ simple NV & no & u.s. \\
\hline Karnath et al. [21], 2005 & 14 subjects & $<14$ days & $\mathrm{R}$ & $\mathrm{V}+$ simple NV & no & u.s. \\
\hline Nimmo-Smith et al. [22], 2005 & 64 subjects & mean 67 days & $\mathrm{R}+\mathrm{L}$ & $\mathrm{V}+\mathrm{NV}$ & no & not included \\
\hline Barskova et al. [23], 2006 & 151 subjects & mean 2.6 months & u.s. & $\mathrm{V}$ & yes & u.s. \\
\hline Santos et al. [24], 2006 & 180 subjects & $<4$ days & $\mathrm{R}+\mathrm{L}$ & $\mathrm{V}$ & no & not included \\
\hline Appelros et al. [25], 2007 & 272 subjects & 1-4 days & $\mathrm{R}+\mathrm{L}$ & $\mathrm{V}+$ simple NV & no & not included \\
\hline Spalletta et al. [26], 2007 & 50 subjects & $<90$ days & $\mathrm{R}$ & $\mathrm{V}+$ simple NV & no & u.s. \\
\hline
\end{tabular}

$\mathrm{R}=$ Right; $\mathrm{L}=$ left; $\mathrm{V}$ = verbal; $\mathrm{NV}$ = non-verbal; u.s. = unspecified.

neoplastic pathologies (table 1). Indeed, data from different aetiologies, if analysed separately, can be very informative to highlight possible similarities and differences in awareness impairments. In contrast, the study of a heterogeneous sample can blur data, since in spite of phenomenological similarities, unawareness deficits can imply very different processes in different patient populations [50].

Time Elapsed from the Acute Event. Anosognosia can evolve rapidly, within a few days or months and more rarely can last for several years after injury [29, 33, 36, 65]. Since anosognosia is more frequent in the acute than in the chronic phase $[51,66]$, the high variability in incidence rates [3] could be partially due to heterogeneous times of testing in different studies. Thus, it is necessary to stress target temporal terms and to discriminate between acute and chronic patients. In addition, these require differential assessment trials, and findings from the two subgroups should be analysed separately. In their meta-analysis, Pia et al. [66] defined as acute the patients tested within 29 days after stroke and as chronic those tested after the 30th postinjury day, and found $48 \%$ of studies focusing on acute patients, $30 \%$ on chronic pa- tients, $9 \%$ on both acute and chronic patients, and in $13 \%$ of studies data about time of testing were not available. Given the high and rapid fluctuations of anosognosia in stroke, very acute cases, ranging from 1 to 7 days from injury, should be further discriminated from acute and subacute ones, ranging from 8 to 29 days after stroke. Consistently, in the sample of studies on stroke selected in the present paper, $35 \%$ of studies recruited very acute patients only, $25 \%$ chronic subjects only, while $40 \%$ combined subjects with variable time of testing.

Laterality of Lesion. In the present review, most of the studies considered (60\%) included patients with both right and left strokes, 35\% right only and no study recruited exclusively subjects with injury on the left. One study did not report information about laterality of lesion. Indeed, patients injured on the left can be more difficult to assess because of possible aphasic deficits, so they tend not to be included $[4,6,66,67]$. However, the exclusion may cause some confusion due to the underestimation of rates of anosognosia in the total brain injury population.

Aphasia. Patients with global or severe comprehension aphasia cannot be tested on their awareness of lan- 
guage disorders, but mere behavioural observation can provide information about awareness of sensorimotor deficits. In contrast, productive aphasia can be handled with some specific administration devices. For instance, the clinician can read the answer alternatives aloud and ask the patient to indicate his/her own choice with gestures or make him/her fill in the questionnaires on his/ her own. In the present review, 55\% of selected studies excluded stroke patients with language disorders, often generally mentioning inadequate linguistic abilities or severe language impairment, while $40 \%$ of studies did not mention the issue at all, with a definite loss of information for the reader.

\section{How to Assess?}

Some methodological aspects play a relevant role in the assessment of anosognosia. In particular, different clinical conditions require different assessment approaches.

Patient Estimation. Obviously, patient estimations of their deficits have to be compared to an objective standard. Clinical judgement is the most frequently adopted criterion in classical anosognosia scales, while awareness questionnaires for TBI and dementia mostly rely upon the direct comparison between patient answers and informant/staff reports. In fact, the total difference score, obtained by subtracting patient from caregiver evaluations, is supposed to reflect the degree of awareness of the patient. Self/significant other comparisons can be quite informative, due to a daily and long-lasting knowledge of the patient [4]. However, in the acute stage following stroke, this methodology is not fully reliable, since relatives and significant others can still have little information; as well, stress, anxiety [68] and denial coping strategy can alter their judgement $[4,33,69]$. In TBI, some measures which specifically examine these aspects have been developed, such as the Revised Patient Competency Rating Scale [68], a subsequent 3-item addition to the original Patient Competency Rating Scale and the Head Injury Behaviour Scale [69]. Both of them ask the caregiver how stressful the patient's problematic behaviours are. While recently a trial to test the differential efficacy of various methodologies in anosognosia assessment in dementia has been carried out [70], to our knowledge an analogous study to determine which approach is more efficient in stroke has not been performed.

Course of Anosognosia. Longitudinal studies can be very informative to follow the course of anosognosia that usually evolves as time goes by. In addition, the frequency of assessment has to be rather high, especially in the acute phase. In spite of this, $30 \%$ of studies on stroke included in our review provided a follow-up and, similarly, Jehkonen et al. [71] reported that in $70 \%$ of studies no follow-up was carried out. However, some pragmatic factors preventing a frequent assessment approach have to be stressed. Firstly, clinical practice and ward routine hardly deal with frequent questionnaire administrations, especially in the very acute stage. Analogously, fatigability, patient's pain and reduced concentration can be salient problems. Thus, in the first days after stroke, assessment should focus strictly on only a few definite issues, not to outwear the subject, and should always explore implicit knowledge of sensorimotor deficits, since the patient may have difficulty in expressing verbally his/her condition. Secondly, early after stroke the patient often has not yet had the chance to put his/her abilities to the test. Analogously, questions about functional implications of the deficit can be misleading, and therefore they should be limited. Finally, at this stage, questions about prognosis can be avoided because of the objective lack of information. In summary, in the acute stage the assessment of awareness deficits has to concern only evident impairments, while it can be too early for a reliable self-evaluation of cognitive abilities, which can be less salient to the patient than a physical deficit.

Scale Type. Dichotomous scales, such as yes/no or aware/unaware, are not very fruitful, since anosognosia is not an all-or-nothing phenomenon. In contrast, Likert scales seem to be the most appropriate to measure depth of awareness and are adopted in most tools. In addition, separate domain scores should be provided to better highlight possible modality specificities.

\section{A Holistic Approach to Anosognosia}

A number of studies showed that awareness of deficits cannot be conceived as an isolated disorder, it must rather be integrated in a holistic view of the patient $[3,50]$. Thus, in association with the assessment procedure specific to anosognosia, we suggest investigating other concurrent dimensions (table 3): (a) general level of cognitive impairment; indeed, the relationship between anosognosia and global cognitive level, as measured for instance by the Mini-Mental State Examination [81] or Wechsler scales [82] is still controversial, since some authors assert that cognitive impairment is not a causal factor of anosognosia, rather a worsening condition $[8,18,33,83,84]$; (b) mnestic functions; because anosognosia has been interpreted in some studies as the result of a mnestic failure, 
Table 3. Fundamental issues of assessment of anosognosia in stroke

Dimensions to investigate How to investigate $\quad$ Existing scales investigating the dimension

\section{Anosognosia}

Awareness of sensorimotor deficits Structured questions addressed to the patient to compare with clinical evidence

Awareness of cognitive deficits
Awareness of emotional and interper-
sonal deficits

\section{Implicit knowledge}

Possible modality specificity of anosognosia

Neighbouring delusional phenomena (anosodiaphoria, somatoparaphrenias, misoplegia, confabulation) Correct evaluation of functional implications of sensorimotor/ cognitive/behavioural deficits in activities of daily living

\section{Structured questions to compare with neuro-} psychological performances

Structured questions to compare with psychopathological and behavioural scales and with caregiver's reports

\section{Clinical trials and requests to perform actions, in} order to compare verbal and procedural knowledge

Separate items for different deficits (e.g. paresis of the arm and/or leg, aphasia, cognitive abilities)

Semi-structured questions addressed to the patient to let emerge possible strange sensations and feelings about the deficit

Structured questions addressed to the patient to compare with clinical evidence
Bisiach's scale, SAI, SADI, PCRS, Anosognosia Questionnaire [8], Anosognosia for Hemiplegia Questionnaire [52]

PCRS, AQ, SADI, Impaired Self-Awareness Scale [64]

PCRS, AQ, HIBS, SADI

SAI, Anosognosia Questionnaire

Bisiach's scale, SAI, PCRS

SAI, Anosognosia Questionnaire, Anosognosia for Hemiplegia Questionnaire

SADI, PCRS, AQ, HIBS
Degree of unawareness

SADI, PCRS, AQ, SAI, Anosognosia

Questionnaire, Anosognosia for Hemiplegia Questionnaire

\begin{tabular}{ll}
\hline Correct causal attribution & Structured questions addressed to the patient \\
\hline Correct evaluation of prognosis & $\begin{array}{l}\text { Structured questions addressed to the patient to } \\
\text { compare with clinical evidence }\end{array}$ \\
\hline Compliance to rehabilitation & $\begin{array}{l}\text { Structured questions addressed to the patient an } \\
\text { to compare with staffs and caregiver's reports }\end{array}$ \\
\hline $\begin{array}{l}\text { Detection of differential signs of } \\
\text { anosognosia and/or psychological } \\
\text { denial }\end{array}$ & $\begin{array}{l}\text { Structured questions to let emerge possible } \\
\text { peculiar behavioural aspects of psychological de }\end{array}$ \\
\hline Neglect & $\begin{array}{l}\text { Specific tests to assess possible association with } \\
\text { neglect phenomena }\end{array}$ \\
\hline
\end{tabular}

SADI, SAI

SADI, LDIS

LDIS

Clinician's Rating Scale for Evaluating

Impaired Self-Awareness and Denial of Disability [64], LDIS

Line crossing, letter cancellation, figure and shape copying, and line bisection tests, trials to assess non-visual neglect forms [72]

\section{Behaviour}

Alexithymia

Scale to assess unawareness of emotions

Mood, anxiety and apathy symptoms Semi-structured scales to assess severity of depression, anxiety states and apathy

Aggressiveness

Structured scale to assess state and trait aggressiveness

\section{Cognition}

Global cognitive level and IQ

Tests to assess general cognitive impairment

Mnestic functions

Tests to assess possible mnestic impairment

Language functions

Executive functions and attention
Tests to assess possible associated language disorders Tests to assess possible attention impairment
TAS-20

HAM-D, HAM-A, Apathy Evaluation Scale [73]

STAXI

SAI = Structured Awareness Interview [18]; PCRS = Patient Competency Rating Scale [74]; SADI = Self-Awareness of Deficit Interview [4]; TAS-20 = Toronto Alexithymia Scale [75], AQ = Awareness Questionnaire [28]; LDIS = Levine Denial of Illness Scale [76]; HIBS = Head Injury Behaviour Scale [69]; HAM-D = Hamilton Depression Scale [77]; HAM-A = Hamilton Anxiety Scale [78]; STAI = State Trait Anxiety Inventory [79]; STAXI = State Trait Anger Expression Inventory [80]; WAIS-R = Wechsler Adult Intelligence Scale, Revised; MMSE = MiniMental State Examination; WCST $=$ Wisconsin Card Sorting Test. 
specifically of the inability to integrate new episodic experiences into long-term memory or the image of oneself [18, 49]; (c) language functions. In some studies, phonemic and semantic abilities in verbal fluency were related to anosognosia $[8,18,33,49]$, although the nature of this relationship is still unclear; (d) executive functions. The relationship between anosognosia deficits and attentional control and inhibition function [85] on the one hand, and set-shifting or cognitive flexibility [86] on the other hand, are to be investigated, given their relevance in other self-awareness disorders [33, 49, 87-90]; (e) psychopathology; as it is necessary to ascertain the relationship between anosognosia and neuropsychiatric symptoms. For instance, in anosognosic patients depression and/or anxiety $[8,30,91]$, apathy $[92,93]$, anger and hostility $[94$, $95]$ and alexithymia $[26,96]$ require further investigation, given their frequency in stroke patients and their controversial role in awareness of illness and patient outcome $[24,30,46,49,64]$.

The administration of these neuropsychological and psychopathological instruments is thought to be necessary on the one hand as a diagnostic procedure to describe the complete clinical picture of the patient, and on the other hand to make possible correlations between anosognosia and neuropsychiatric features in stroke patients. In table 3 , some examples of neuropsychiatric scales validated in stroke patients are given.

Finally, neuro-imaging studies should be part of the diagnostic trial. In fact, a combination of data from conventional or, more interestingly, non-conventional magnetic resonance imaging measures, such as diffusion tensor imaging or tractography, with behavioural data, could provide relevant information about brain circuits involved in specific dimensions of self-awareness and their deficits, analogously to the investigations carried out in other pathological conditions [97-99]. Currently, these methods are still not completely automated and require the supervision of technical experts. However, despite the time they require, the information they provide may help clinicians to optimize individual rehabilitation programmes in the near future. Also, advanced methods for studying structural indices in the cortex, such as thickness, in association with methods for studying functional activation, permit to follow the process of cerebral plasticity following the recovery from awareness deficits [100]. This might explain, if appropriately validated, reasons why patients may fully recover within a few hours or may become chronic cases.

\section{Conclusions}

Anosognosia represents a stimulating challenge for clinicians, due to its remarkable incidence in stroke populations [3], phenomenological variability and effect on the rehabilitation course and the patient's quality of life. Given the complexity of this phenomenon, similar to other multidimensional fields such as neuropsychology or psychopathology, a reliable assessment procedure for anosognosia is necessary. In spite of their good reliability, present diagnostic questionnaires are not fully exhaustive in catching the multifaceted anosognosic phenomena. In fact, as the model of Crosson et al. [7] illustrates, awareness is not a unitary function, and the deficit can regard different components which can determine important features for the development of a specific rehabilitation treatment. In addition, anosognosia is no longer conceived merely as the unawareness of a deficit per se but implies a number of related factors, such as attribution, expectations of recovery, psychological denial, need for rehabilitation and estimation of functional limitations. Such a wide perspective on anosognosia requires an articulated assessment in order to gain a more definite diagnosis, to develop specific rehabilitation programmes and to understand more deeply awareness and related superior neuropsychological processes. Thus, we have outlined the main dimensions to include them in a flexible and comprehensive assessment procedure for anosognosia. Our approach aims to take into consideration the patient in his/her wholeness, in accordance with modern holistic perspectives in medicine, and therefore also involves cognitive, neuropsychiatric and behavioural factors.

Another remarkable issue is the specificity of various clinical situations which require partially different assessment modalities. For instance, for acute-phase subjects and in general for patients showing vigilance deficits, severe cognitive impairment, non-compliance, severe language disturbances or behavioural disorders, a more basic set of measures is suitable. Thus, a few instruments focusing on awareness of sensorimotor impairments, possible implicit knowledge, somatoparaphrenias, global cognitive assessment, language functions and neglect could be administered. On the other hand, patients showing persistent anosognosia have to be monitored regularly and as frequently as possible to detect any evolution of anosognosia, which in brain-injured subjects can be very sudden. For instance, a very acute-stage administration, such as within 3 days from stroke, has to be followed by regular consecutive administrations. 
Another frequent problem is represented by aphasia. In our opinion, aphasia should not necessarily be an exclusion criterion for the assessment of anosognosia, since in productive and moderate language disorders specific non-verbal assessment methods can be adopted.
In conclusion, this paper is intended to be a first step towards a more definite, reliable and valid diagnostic methodology, which should be structured ex novo considering the multifaceted expression of anosognosia and the complexity of its interaction with behaviour, cognition and with general clinical aspects.

\section{References}

1 Antoine C, Antoine P, Guermonprez P, Frigard B: Awareness of deficits and anosognosia in Alzheimer's disease. Encéphale 2004;30: 570-577.

2 Prigatano G, Johnson S: The three vectors of consciousness and their disturbances after brain injury. Neuropsychol Rehabil 2003;13: 13-29.

- 3 Orfei MD, Robinson RG, Prigatano GP, Starkstein S, Rüsch N, Bria P, Caltagirone C, Spalletta G: Anosognosia for hemiplegia after stroke is a multifaceted phenomenon: a systematic review of the literature. Brain 2007;130:3075-3090

4 Fleming JM, Strong J, Ashton R: Self-awareness of deficits in adults with traumatic brain injury: how best to measure? Brain Inj 1996; 10:1-15

5 Gialanella B, Monguzzi V, Santoro R, Rocchi $S$ : Functional recovery after hemiplegia in patients with neglect: the rehabilitative role of anosognosia. Stroke 2005;36:2687-2690.

6 Pedersen PM, Jørgensen HS, Nakayama H, Raaschou HO, Olsen TS: Frequency, determinants and consequences of anosognosia in acute stroke. J Neurol Rehabil 1996;40: 367-377.

7 Crosson C, Barco PP, Velozo C, Bolesta MM, Cooper PV, Werts D, Brobeck TC: Awareness and compensation in postacute head injury rehabilitation. J Head Trauma Rehabilitation 1989;4:46-54

$\checkmark 8$ Starkstein SE, Fedoroff JP, Price TR, Leiguarda R, Robinson RG: Anosognosia in patients with cerebrovascular lesions: a study of causative factors. Stroke 1992;23:1446-1453.

-9 Stone SP, Halligan PW, Greenwood RJ: The incidence of neglect phenomena and related disorders in patients with an acute right or left hemisphere stroke. Age Ageing 1993; 22:46-52.

10 Ramachandran VS: Anosognosia in parietal lobe syndrome. Conscious Cogn 1995;4:2251.

-11 Maeshima S, Dohi N, Funahashi K, Nakai K, Itakura T, Komai N: Rehabilitation of patients with anosognosia for hemiplegia due to intracerebral haemorrhage. Brain Inj 1997;11:691-697.

12 Jehkonen M, Ahonen JP, Dastidar P, Laippala P, Vilkki J: Unawareness of deficits after right hemisphere stroke: double-dissociations of anosognosias. Acta Neurol Scand 2000;102:378-384
13 Hartman-Maeir A, Soroker N, Katz N: 25 Appelros P, Karlsson GM, Hennerdal S: Anosognosia for hemiplegia in stroke rehabilitation. Neurorehabil Neural Repair 2001;15:213-222.

14 Appelros P, Karlsson GM, Seiger A, Nydevik I: Neglect and anosognosia after first-ever stroke: incidence and relationship to disability. J Rehabil Med 2002;34:215-220.

5 Appelros P, Karlsson GM, Seiger A, Nydevik I: Prognosis for patients with neglect and anosognosia with special reference to cognitive impairment. J Rehabil Med 2003;35:254258.

16 Hartman-Maeir A, Soroker N, Oman SD, Katz N: Awareness of disabilities in stroke rehabilitation - a clinical trial. Disabil Rehabil 2003;25:35-44

17 Farnè A, Buxbaum LJ, Ferraro M, Frassinetti F, Whyte J, Veramonti T, Angeli V, Coslett HB, Ladavas E: Patterns of spontaneous recovery of neglect and associated disorders in acute right brain-damaged patients. J Neurol Neurosurg Psychiatry 2004;75:1401-1410.

18 Marcel AJ, Tegner R, Nimmo-Smith I: Anosognosia for plegia: specificity, extension, partiality and disunity of bodily unawareness. Cortex 2004;40:19-40.

19 Baier B, Karnath HO: Incidence and diagnosis of anosognosia for hemiparesis revisited. J Neurol Neurosurg Psychiatry 2005;76:358361.

20 Berti A, Bottini G, Gandola M, Pia L, Smania N, Stracciari A, Castiglioni I, Vallar G, Paulesu E: Shared cortical anatomy for motor awareness and motor control. Science 2005;309:488-491.

21 Karnath HO, Baier B, Nagele T: Awareness of the functioning of one's own limbs mediated by the insular cortex? J Neurosci 2005;25: 7134-7138.

22 Nimmo-Smith I, Marcel AJ, Tegner R: A diagnostic test of unawareness of bilateral motor task abilities in anosognosia for hemiplegia. J Neurol Neurosurg Psychiatry 2005; 76:1167-1169.

23 Barskova T, Wilz G: Psychosocial functioning after stroke: psychometric properties of the patient competency rating scale. Brain Inj 2006;20:1431-1437.

24 Santos CO, Caeiro L, Ferro JM, Albuquerque R, Luisa Figueira M: Anger, hostility and aggression in the first days of acute stroke. Eur J Neurol 2006;13:351-358.
Anosognosia versus unilateral neglect. Coexistence and their relations to age, stroke severity, lesion site and cognition. Eur J Neurol 2007;14:54-59.

26 Spalletta G, Serra L, Fadda L, Ripa A, Bria P, Caltagirone C: Unawareness of motor impairment and emotions in right hemispheric stroke: a preliminary investigation. Int J Geriatr Psychiatry 2007;22:1241-1246.

27 Prigatano GP, Altman IM: Impaired awareness of behavioral limitations after traumatic brain injury. Arch Phys Med Rehabil 1990;71:1058-1064.

28 Sherer M, Bergloff P, Boake C, High W Jr, Levin E: The Awareness Questionnaire: factor structure and internal consistency. Brain Inj 1998;12:63-68

29 Leathem JM, Murphy LJ, Flett RA: Self and informant-ratings on the Patient Competency Rating Scale in patients with traumatic brain injury. J Clin Exp Neuropsychol 1998; 20:694-705.

30 Fleming JM, Strong J, Ashton R: Cluster analysis of self-awareness levels in adults with traumatic brain injury and relationship to outcome. J Head Trauma Rehabil 1998;13: 39-51.

31 Ranseen JD, Bhaska LA, Schmitt FA: An investigation of anosognosia following traumatic head injury. Int J Clin Neuropsychol 1990;12:29-36.

32 Sherer M, Hart T, Nick TG: Measurement of impaired self-awareness after traumatic brain injury: a comparison of the Patient Competency Rating Scale and the Awareness Questionnaire. Brain Inj 2003;17:25-37.

33 Bogod NM, Mateer CA, MacDonald SWS: Self-awareness after traumatic brain injury: a comparison of measures and their relationship to executive functions. J Int Neuropsychol Soc 2003;9:450-458.

34 Hart T, Sherer M, Whyte J, Polansky M, Novack TA: Awareness of behavioral, cognitive, and physical deficits in acute traumatic brain injury. Arch Phys Med Rehabil 2004;85:14501456

35 Evans CC, Sherer M, Nick TG, Nakase-Richardson R, Yablon SA: Early impaired selfawareness, depression, and subjective wellbeing following traumatic brain injury. J Head Trauma Rehabil 2005;20:488-500. 
\36 Murrey GJ, Hale FM, Williams JD: Assessment of anosognosia in persons with frontal lobe damage: clinical utility of the MayoPortland adaptability inventory (MPAI). Brain Inj 2005; 19:599-603.

>37 Sawchyn JM, Mateer CA, Suffield JB: Awareness, emotional adjustment, and injury severity in postacute brain injury. J Head Trauma Rehabil 2005;20:301-314.

-38 Sherer M, Hart T, Whyte J, Nick TG, Yablon SA: Neuroanatomic basis of impaired selfawareness after traumatic brain injury. J Head Trauma Rehabil 2005;20:287-300.

\$3 Kurtz JE, Putnam SH: Patient-informant agreement on personality ratings and selfawareness after head injury. Clin Neuropsychol 2006;20:453-468.

40 Schmitz TW, Rowley HA, Kawahara TN, Johnson SC: Neural correlates of self-evaluative accuracy after traumatic brain injury. Neuropsychologia 2006;44:762-773.

-41 Pagulayan KF, Temkin NR, Machamer JE, Dikmen SS: The measurement and magnitude of awareness difficulties after traumatic brain injury: a longitudinal study. J Int Neuropsychol Soc 2007;13:561-570.

42 Dirette DK, Plaisier BR: The development of self-awareness of deficits from 1 week to 1 year after traumatic brain injury: preliminary findings. Brain Inj 2007;21:1131-1136.

$\checkmark 43$ Bisiach E, Vallar G, Perani D, Papagno C, Berti A: Unawareness of disease following lesions of the right hemisphere: anosognosia for hemiplegia and anosognosia for hemianopia. Neuropsychologia 1986;24:471482.

44 Teasdale TW, Christensen AL, Willmes K, Deloche G, Braga L, Stachowiak F, Vendrell JM, Castro-Caldas A, Laaksonen RK, Leclercq M: Subjective experience in brain-injured patients and their close relatives: a European Brain Injury Questionnaire study. Brain Inj 1997;11:543-563.

-45 Borgaro SR, Prigatano GP: Modification of the Patient Competency Rating Scale for use on an acute neurorehabilitation unit: the PCRS-NR. Brain Inj 2003;17:847-853.

-46 Kortte KB, Wegener ST, Chwalisz K: Anosognosia and denial: their relationship to coping and depression in acquired brain injury. Rehabil Psychol 2003;48:131-136.

-47 Fischer S, Gauggel S, Trexler LE: Awareness of activity limitations, goal setting and rehabilitation outcome in patients with brain injuries. Brain Inj 2004;18:547-562.

-48 Fischer S, Trexler LE, Gauggel S: Awareness of activity limitations and prediction of performance in patients with brain injuries and orthopedic disorders. J Int Neuropsychol Soc 2004;10:190-199.

-49 Noé E, Ferri J, Caballero MC, Villodre R, Sanchez A, Chirivella J: Self-awareness after acquired brain injury: predictors and rehabilitation. J Neurol 2005;252:168-175.
50 Orfei MD, Robinson RG, Bria P, Caltagirone C, Spalletta G: Unawareness of illness in neuropsychiatric disorders: phenomenological certainty versus etiopathogenic vagueness. Neuroscientist 2008;14:203-222.

51 Cutting J: Study of anosognosia. J Neurol Neurosurg Psychiatry 1978;41:548-555.

52 Feinberg TE, Roane DM, Ali J: Illusory limb movements in anosognosia for hemiplegia. J Neurol Neurosurg Psychiatry 2000;68:511513.

53 Babinski J: Contribution à l'étude de troubles mentaux dans l'hémiplégie organique cérébrale. Rev Neurol 1914;27:845-847.

54 Frith CD, Blakemore SJ, Wolpert DM: Abnormalities in the awareness and control of action. Philos Trans R Soc Lond B Biol Sci 2000;355:1771-1788.

55 Heilman KM, Barrett AM, Adair JC: Possible mechanisms of anosognosia: a defect in self-awareness. Philos Trans R Soc Lond B Biol Sci 1998;353:1903-1909.

56 Vallar G, Ronchi R: Anosognosia for motor and sensory deficits after unilateral brain damage: a review. Restor Neurol Neurosci 2006;24:247-257.

57 Vuilleumier P: Anosognosia: the neurology of beliefs and uncertainties. Cortex 2004;40: 9-17.

58 Bach LJ, David AS: Self-awareness after acquired and traumatic brain injury. Neuropsychol Rehabil 2006;16:397-414.

59 Fischer S, Gauggel S, Trexler LE: Awareness of activity limitations, goal setting and rehabilitation outcome in patients with brain injuries. Brain Inj 2004;18:547-562.

60 Schacter DL: Toward a cognitive neuropsychology of awareness: implicit knowledge and anosognosia. J Clin Exp Neuropsychol 1990;12:155-178.

61 Fischer S, Trexler LE, Gauggel S: Awareness of activity limitations and prediction of performance in patients with brain injuries and orthopedic disorders. J Int Neuropsychol Soc 2004;10:190-199.

-62 Hart T, Giovannetti T, Montgomery MW, Schwartz MF: Awareness of errors in naturalistic action after traumatic brain injury. J Head Trauma Rehabil 1998;13:16-28.

63 Brozzoli C, Dematte ML, Pavani F, Frassinetti F, Farne A: Neglect and extinction: within and between sensory modalities. $\mathrm{Re}$ stor Neurol Neurosci 2006;24:217-232.

64 Prigatano GP, Klonoff PS: A clinician's rating scale for evaluating impaired self-awareness and denial of disability after brain injury. Clin Neuropsychol 1998;12:56-67.

65 Prigatano GP, Schacter DL: Awareness of Deficit after Brain Injury: Clinical and Theoretical Issues. New York, Oxford University Press, 1991.

66 Pia L, Neppi-Modona M, Ricci R, Berti A: The anatomy of anosognosia for hemiplegia: a meta-analysis. Cortex 2004;40:367-377.
67 Jehkonen M, Laihosalo M, Kettunen JE: Impact of neglect on functional outcome after stroke: a review of methodological issues and recent research findings. Restor Neurol Neurosci 2006;24:209-215.

68 Prigatano GP, Borgaro S, Baker J, Wethe J: Awareness and distress after traumatic brain injury: a relative's perspective. J Head Trauma Rehabil 2005;20:359-367.

69 Godfrey HP, Harnett MA, Knight RG, Marsh NV, Kesel DA, Partridge FM, Robertson RH: Assessing distress in caregivers of people with a traumatic brain injury (TBI): a psychometric study of the Head Injury Behaviour Scale. Brain Inj 2003;17:427-435.

70 Hannesdottir K, Morris RG: Primary and secondary anosognosia for memory impairment in patients with Alzheimer's disease. Cortex 2007;43:1020-1030.

71 Jehkonen M, Laihosalo M, Kettunen J: Anosognosia after stroke: assessment, occurrence, subtypes and impact on functional outcome reviewed. Acta Neurol Scand 2006; 114:293-306.

72 Lindell AB, Jalas MJ, Tenovuo O, Brunila T, Voeten MJ, Hamalainen H: Clinical assessment of hemispatial neglect: evaluation of different measures and dimensions. Clin Neuropsychol 2007;21:479-497.

73 Marin RS, Biedrzycki RC, Firinciogullari S: Reliability and validity of the Apathy Evaluation Scale. Psychiatry Res 1991;38:143162 .

74 Prigatano GP, Fordyce DJ, Zeiner HK, Roueche JR, Pepping M, Wood BC: Neuropsychological Rehabilitation after Brain Injury. Baltimore, Johns Hopkins University Press, 1986.

75 Bagby RM, Taylor GJ, Parker JD: The Twenty-Item Toronto Alexithymia Scale. II. Convergent, discriminant, and concurrent validity. J Psychosom Res 1994;38:33-40.

76 Levine J, Warrenburg S, Kerns R, Schwartz G, Delaney R, Fontana A, Gradman A, Smith $\mathrm{S}$, Allen S, Cascione R: The role of denial in recovery from coronary heart disease. Psychosom Med 1987;49:109-117.

77 Hamilton M: A rating scale for depression. J Neurol Neurosurg Psychiatry 1960;12:5662.

78 Hamilton M: The assessment of anxiety states by rating. Br J Med Psychol 1959;32: 50-55.

79 Spielberger CD, Gorsuch RL, Lurshene RE: Test Manual for the State-Trait Anxiety Inventory. Palo Alto, CA, Consulting Psychologists Press, 1970.

80 Spielberger CD: State-Trait Anger Expression Inventory, Research Edition - Professional Manual. Odessa, Psychological Assessment Resources, 1988.

81 Folstein MF, Folstein SE, McHugh PR: 'MiniMental State': a practical method for grading the cognitive state of patients for the clinician. J Psychiatr Res 1975;12:189-198. 
82 Wechsler D: WAIS-R Manual: Wechsler Adult Intelligence Scale - Revised. San Antonio, Psychological Corporation, 1981.

83 Davies M, Davies AA, Coltheart M: Anosognosia and the two-factor theory of delusions. Mind Lang 2005;20:209-236.

84 Levine DN, Calvanio R, Rinn WE: The pathogenesis of anosognosia for hemiplegia. Neurology 1991;41:1770-1781.

85 Stroop JR: Studies of interference in serial verbal reactions. J Exp Psychol 1935;12:643662.

86 Heaton R: Wisconsin Card Sorting Test Manual. Odessa, Psychological Assessment Resources, 1981.

-87 Kashiwa Y, Kitabayashi Y, Narumoto J, Nakamura K, Ueda H, Fukui K: Anosognosia in Alzheimer's disease: association with patient characteristics, psychiatric symptoms and cognitive deficits. Psychiatry Clin Neurosci 2005;59:697-704.

88 Michon A, Deweer B, Pillon B, Agid Y, Dubois B: Relation of anosognosia to frontal lobe dysfunction in Alzheimer's disease. J Neurol Neurosurg Psychiatry 1994;57:805809.
89 Subotnik KL, Nuechterlain KH, Irzhevsky V, Kitchen CM, Woo SM, Mintz J: Is unawareness of psychotic disorder a neurocognitive or psychological defensiveness problem? Schizophr Res 2005;75:147-157.

$\checkmark 90$ Shad MU, Muddasani S, Prasad K, Sweeney JA, Keshavan MS: Insight and prefrontal cortex in first-episode schizophrenia. Neuroimage 2004;22:1315-1320.

-91 Spalletta G, Ripa A, Bria P, Caltagirone C, Robinson RG: Response of emotional unawareness after stroke to antidepressant treatment. Am J Geriatr Psychiatry 2006; 14:220-227.

$\$ 92$ Brodaty H, Sachdev PS, Withall A, Altendorf A, Valenzuela MJ, Lorentz L: Frequency and clinical, neuropsychological and neuroimaging correlates of apathy following stroke - the Sydney Stroke Study. Psychol Med 2005;35:1707-1716.

-93 Hama S, Yamashita H, Shigenobu M, Watanabe A, Hiramoto K, Kurisu K, Yamawaki S, Kitaoka T: Depression or apathy and functional recovery after stroke. Int J Geriatr Psychiatry 2007;22:1046-1051.

94 Ghika-Schmid F, Bogousslavsky J: Affective disorders following stroke. Eur Neurol 1997;38:75-81
95 Kim JS, Choi S, Kwon SU, Seo YS: Inability to control anger or aggression after stroke. Neurology 2002;58:1106-1108.

96 Spalletta G, Pasini A, Costa A, De Angelis D, Ramundo N, Paolucci S, Caltagirone C: Alexithymic features in stroke: effects of laterality and gender. Psychosom Med 2001; 63:944-950.

$\checkmark 97$ Flashman LA, McAllister TW, Johnson SC, Rick JH, Green RL, Saykin AJ: Specific frontal lobe subregions correlated with unawareness of illness in schizophrenia: a preliminary study. J Neuropsychiatry Clin Neurosci 2001;13:255-257.

98 Ruby P, Schmidt C, Hogge M, D’Argembeau A, Collette F, Salmon E: Social mind representation: where does it fail in frontotemporal dementia? J Cogn Neurosci 2007;19: 671-683.

-99 Shad MU, Muddasani S, Keshavan MS: Prefrontal subregions and dimensions of insight in first-episode schizophrenia - a pilot study. Psychiatry Res 2006;146:35-42.

100 Schaechter JD, Moore CI, Connell BD, Rosen BR, Dijkhuizen RM: Structural and functional plasticity in the somatosensory cortex of chronic stroke patients. Brain 2006;129:2722-2733. 